\title{
e-RA: Regularização Ambiental Online
}

\author{
Luci A. Nicolau, Mateus C. Pereira ${ }^{2}$, Jaime D. C. Mendes $^{3}$, Clodoveu A. Davis Jr. ${ }^{1}$ \\ ${ }^{1}$ Dep. de Ciência da Computação - Universidade Federal de Minas Gerais (UFMG) \\ ${ }^{2}$ Secretaria de Administração Prisional de Minas Gerais \\ ${ }^{3}$ Houer Tecnologia \\ \{luci.nicolau, clodoveu\} @dcc.ufmg.br, mateus.pereira@seap.mg.gov.br, \\ jaimedaniel@houer.com.br
}

\begin{abstract}
Resumo. Este artigo propõe uma aplicação web para levantamento e precificação da documentação referente à regularização ambiental em Minas Gerais. O processo para obtenção de uma licença é constituído de cinco etapas: 1-caracterização, 2enquadramento CNAE, 3-formalização, 4-análise e 5-julgamento, sendo que nas etapas 1 e 2 os recursos humanos e financeiros demandados são significativos e passiveis de erros. A aplicação busca auxiliar na transparência e assertividade da documentação exigida pela lei, minimização dos erros de enquadramento e cobranças relacionadas.
\end{abstract}

\begin{abstract}
This article proposes a Web application for the identification and cost determination of the documentation regarding environmental regulation in Minas Gerais. The process of obtaining a license comprises five stages: 1-characterization, 2-activity classification, 3-formalization, 4-analysis and 5-evaluation, observing that in stages 1 and 2 the human and financial resources required are significant and susceptible to errors. The application seeks to assist in the transparency and assertiveness of documentation required by law, minimizing classification errors and the resulting costs.
\end{abstract}

\section{Introdução}

A obtenção de uma licença para intervenção no meio ambiente é indispensável a todo empreendedor cuja atividade econômica se relacione, em maior ou menor escala, com meio em que está inserida e seu entorno direto. Após a instituição da Política Nacional do Meio Ambiente, Lei 6.938/1981 (Brasil, 1981), foi estabelecido o licenciamento ambiental, obrigatório para todos os entes da federação, de acordo com suas competências. O licenciamento ambiental provê determinações voltadas ao equilíbrio entre exploração econômica e ambiente, sendo portanto, parte fundamental no processo de desenvolvimento sustentável e gerando, em caso de não cumprimento ou não conformidade, punições previstas em lei [BRASIL (2007), MINAS GERAIS (2017)].

O processo para obtenção ou renovação de uma licença ambiental em Minas Gerais é regido por uma deliberação normativa emitida pelo Conselho Estadual de Política Ambiental (COPAM) em 2004 e atualizada em 2017, em etapas: (1) caracterização do empreendimento, (2) enquadramento, (3) formalização, (4) análise, e (5) julgamento [MINAS GERAIS, 2017]. Nas etapas 1 e 2 o requerente providencia um conjunto de documentos que caracterize e posteriormente, enquadre seu empreendimento a partir da classificação nacional de atividades econômicas (CNAE) já informada, e efetua pagamento referente a essas etapas. Na etapa 3 os documentos são apresentados em uma das nove Superintendências Regionais de Meio Ambiente (SUPRAMs), onde é realizada uma conferência manual e individual e, havendo conformidade, se dará o registro formal da solicitação da licença ambiental. Na etapa 4, um técnico capacitado analisa a documentação e fornece um parecer sobre a viabilidade econômico-ambiental do empreendimento. Por fim, na etapa 5, ocorre o julgamento do pedido de licença por um órgão deliberativo instituído, que decide por sua concessão ou denegação. 
Embora definido, esse processo é demorado e pode ser oneroso, podendo ser necessário o investimento de milhões de reais nas etapas 1 e 2 , o que as torna críticas no processo de solicitação de uma licença ambiental. Nessas etapas o empreendedor deverá se informar sobre quais documentos deverá providenciar ou contratar um consultor técnico que o faça. Deverá ser cuidadosamente apresentada a correspondência entre a caracterização do empreendimento e o enquadramento, já que falhas podem gerar custos, recusa no ato de formalização/análise ou julgamento [MINAS GERAIS, 2017]. O motivo da recusa para concessão de uma licença pode ser, por exemplo, que o empreendimento proposto esteja localizado em uma área de preservação ambiental. Logo, é necessário que empreendedores e poder concedente disponham de mecanismos de fácil acesso, por exemplo em ambiente Web, que permitam a verificação de possíveis interseções entre áreas [(ARAÚJO et al., 2009), (GONZÁLEZ, 2019)]. Outro fator relevante para a análise do pedido de licenciamento é o equilíbrio entre o impacto causado pelo empreendimento e sua sustentabilidade socioeconômica. Ghaemi et al. (2009) e Del Campo (2017) desenvolveram aplicações Web que analisam os dados referentes ao pedido de concessão relacionando múltiplos critérios, e apresentam diferentes cenários para uma tomada de decisão dos órgãos gestores quanto à concessão ou não de um licenciamento. Embora, a aplicação proposta nesse trabalho não tenha esse objetivo de modo explícito, a documentação solicitada ao empreendedor oferece subsídios à essa inferência, uma vez que a etapa de enquadramento requer o detalhamento do potencial poluidor.

Frente a esse cenário, este trabalho propõe uma aplicação Web, $e-R A$, que possibilita realizar a caracterização e enquadramento de um empreendimento. A aplicação permite calcular o custo das licenças solicitadas de acordo com a documentação de referência, minimizando a possibilidade de erros em classificações, enquadramentos e valores.

\section{2. $e-R A$ :Regularização ambiental online}

A aplicação $e-R A$ destina-se a apoiar as etapas 1 (caracterização do empreendimento) e 2 (enquadramento) da regularização ambiental em Minas Gerais, pois essas etapas concentram investimentos de recursos humanos e financeiros. Por limitações de espaço, é apresentado apenas a parte do fluxograma do processo de regularização ambiental referente às etapas 1 e 2 . O fluxograma indica dois atores, empreendedor e sistema, identificados em hexágonos pelas letras A e B, respectivamente. Círculos vermelhos ao longo do fluxo identificam a finalização de uma parte do processo.

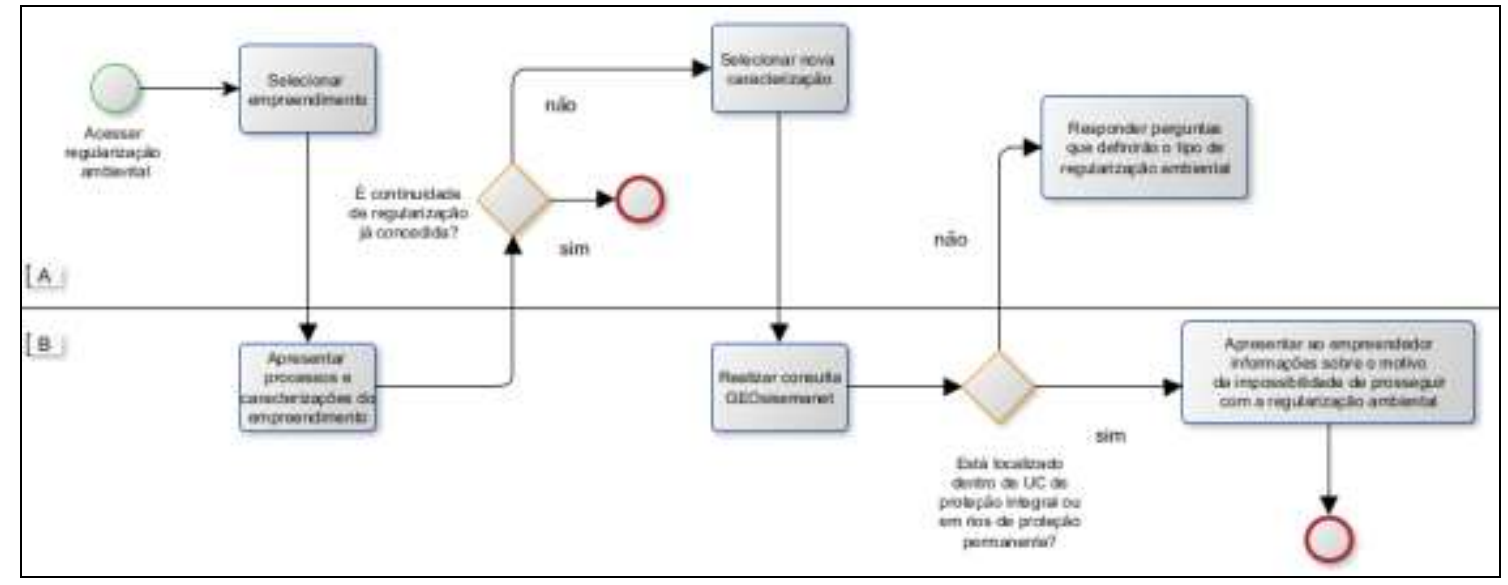

Figura 1: Fluxo para caracterização do empreendimento

A primeira etapa do processo de regularização ambiental no $e-R A$ é a caracterização do empreendimento (Figura 1), na qual o empreendedor informa os dados básicos do empreendimento para primeira autorização ou para ampliação e revalidação. O Sistema será 
responsável por verificar possíveis interseções entre a área pretendida para o empreendimento e áreas protegidas. Na etapa seguinte (Figura 2) o empreendedor informa todas as atividades que pretende realizar no espaço, bem como o estágio atual do empreendimento: Projeto, Instalação ou Operação. O sistema verificará a correspondência entre a atividade informada e classificação nacional de atividades econômicas (CNAE) e, havendo aderência, dar-se-á o enquadramento.

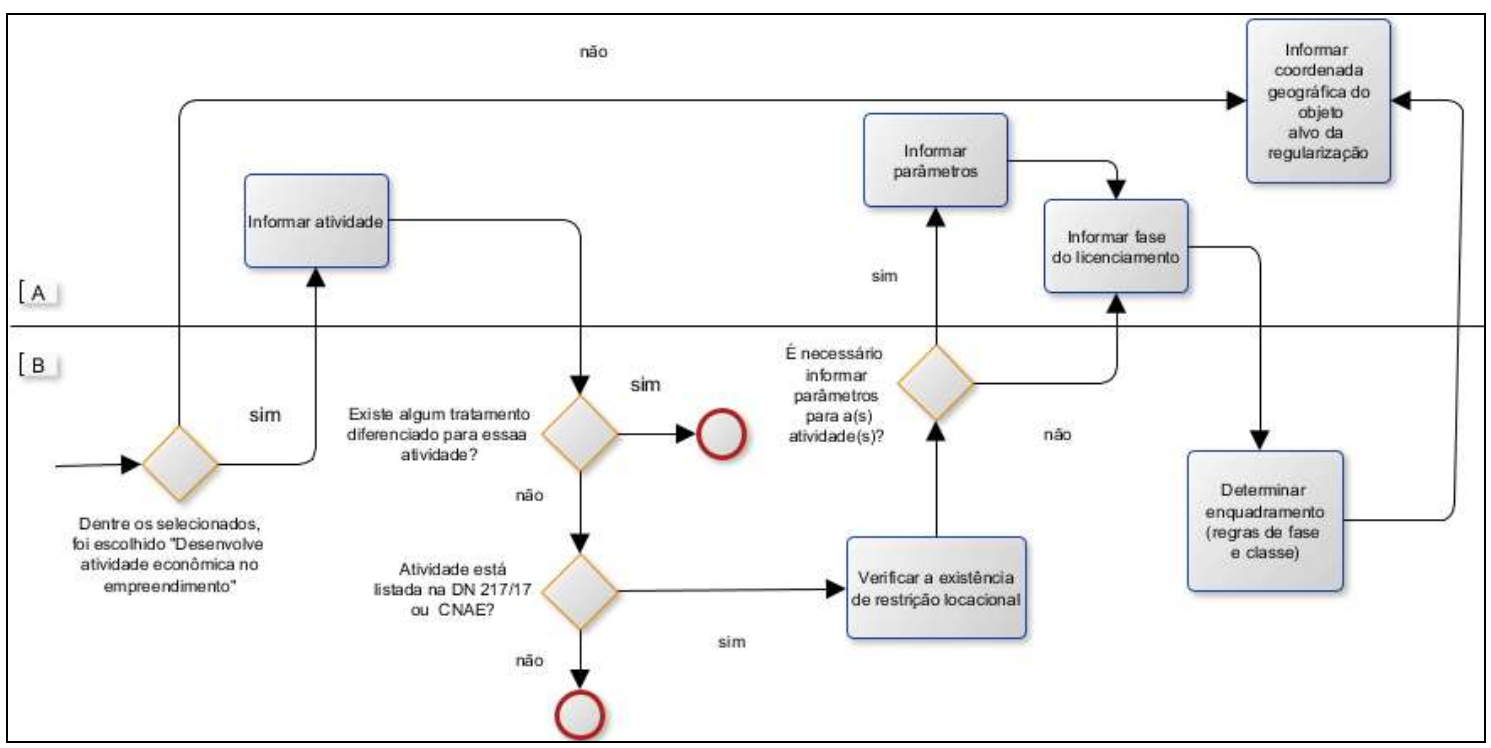

Figura 2: Enquadramento na classificação nacional de atividades econômicas (CNAE)

Informações adicionais a respeito das atividades que se pretende realizar podem ser inseridas, tais como área destinada ao acúmulo de resíduos, coordenadas geográficas e número de empregados pretendidos. A partir das informações inseridas o e-RA fará a correspondência entre as informações que caracterizam o empreendimento, atividade econômica e seu potencial poluidor (Figura 3), fornecendo como resultado a listagem da documentação que deverá ser providenciada e os custos correspondentes.

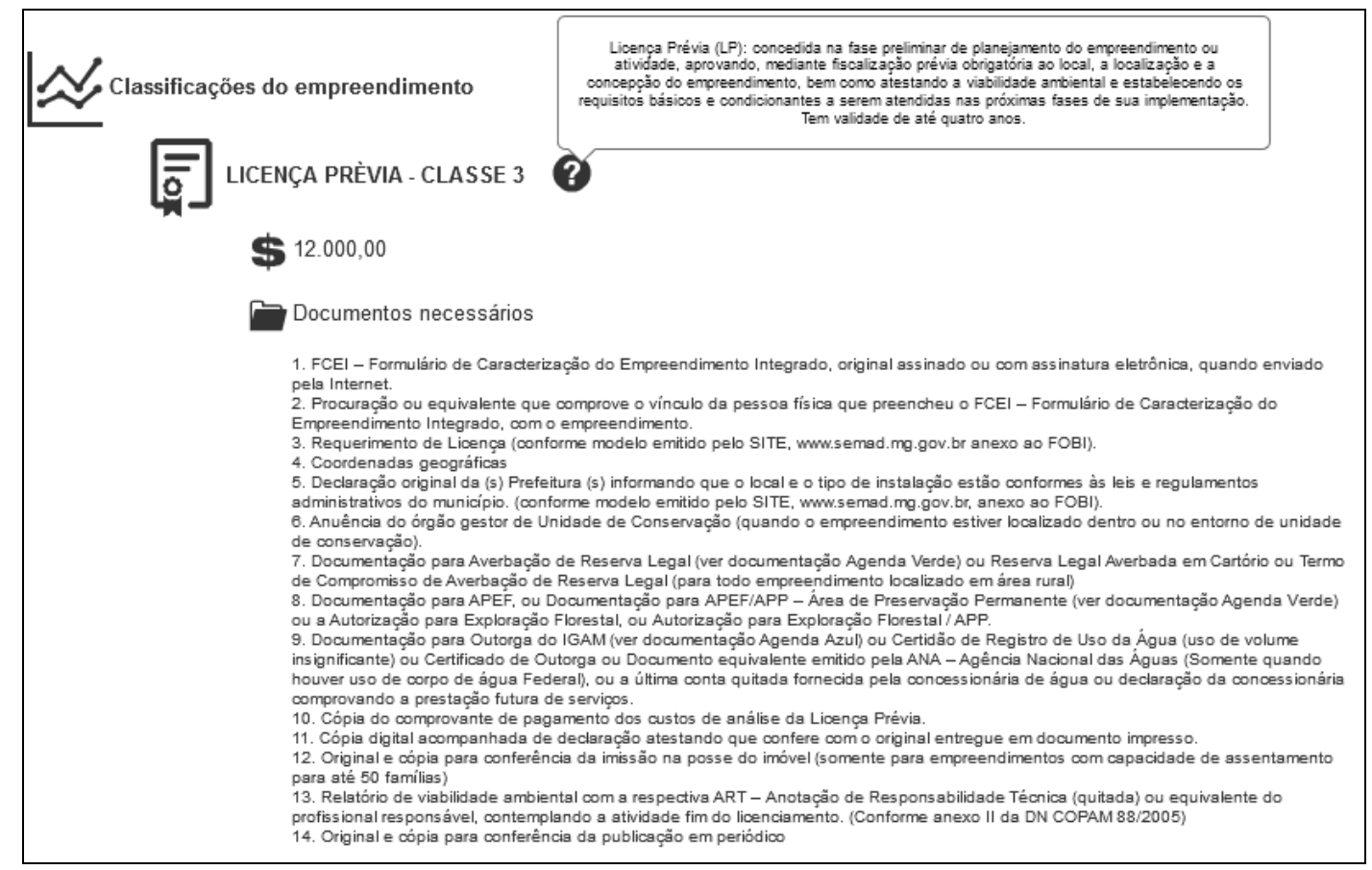

Figura 3: Preços e documentação necessária à solicitação da regularização ambiental 


\section{Conclusão}

O licenciamento ambiental é uma obrigação imposta a todo empreendedor que pretenda realizar quaisquer tipos de intervenção no meio ambiente. Como se trata de atividade essencial e prévia à iniciativa de criação de novos empreendimentos com impacto ambiental potencial, o licenciamento é muitas vezes visto como um impedimento burocrático, gerando uma imagem equivocada de se colocar em oposição ao desenvolvimento econômico. Compete, portanto, ao poder público não apenas aplicar corretamente os procedimentos de licenciamento previstos em Lei, mas também buscar reduzir o desperdício de esforços para que o licenciamento possa ser solicitado e, caso julgado adequado, concedido com custos e prazos razoáveis.

O presente trabalho apresenta iniciativa voltada para a simplificação do processo de solicitação de regularização ambiental, buscando simultaneamente reduzir as possibilidades de erro, que levam a retrabalho e novos custos. Existem grandes oportunidades para aplicação de ciência e tecnologia de geoinformação para o licenciamento ambiental, inclusive em apoio às etapas 4 (análise) e 5 (julgamento). A criação e organização de infraestruturas de dados espaciais em apoio à atividade de licenciamento, por exemplo, é desejável para o futuro próximo.

É possível estender a arquitetura proposta para o aplicativo e-RA para permitir a conexão a repositórios de dados geográficos e estabelecer meios de integração das etapas voltadas ao empreendedor às etapas voltadas para o órgão licenciador.

\section{Referências}

Araújo, L. B., Nagliati, M. D. M., Vendrusculo, L. G., \& Silva, J. (2009). Sistema de busca avançada de dados espaciais voltados ao licenciamento ambiental do Mato Grosso do Sul. In: Simpósio de Geotecnologias no, 2., 2009, Corumbá, MS. Anais... Campinas: Embrapa Informática Agropecuária; São José dos Campos: INPE, 2009.

Brasil. Lei no 6.938, de 31 de agosto de 1981. (1981) Dispõe sobre a Política Nacional do Meio Ambiente. Diário Oficial da União, Brasília, 1981. Disponível em http://www.planalto.gov.br/ccivil_03/Leis/L6938.htm. Acesso em: mar. 2019.

Brasil. Tribunal de Contas da União. Cartilha de licenciamento ambiental (2007). Brasília: TCU, Secretaria de Fiscalização de Obras e Patrimônio da União, 2ed. 84p

Del Campo, A. G. (2017). Mapping environmental sensitivity: A systematic online approach to support environmental assessment and planning. Environmental Impact Assessment Review, 66, 86-98.

Ghaemi, P., Swift, J., Sister, C., Wilson, J. P., \& Wolch, J. (2009). Design and implementation of a web-based platform to support interactive environmental planning. Computers, Environment and Urban Systems, 33(6), 482-491.

González, A., Gleeson, J., \& McCarthy, E. (2019). Designing and developing a web tool to support Strategic Environmental Assessment. Environmental modelling \& software, 111, 472-482.

Minas Gerais. Deliberação Normativa Copam no 217, de 6 de dezembro de 2017 (2017). Disponível em: http://www.siam.mg.gov.br/sla/download.pdf?idNorma=45558 Acesso em: mar 2019 